\title{
THE RESTING HYPERVENTILATION OF CONGENITAL HEART DISEASE*
}

\author{
BY \\ R. J. SHEPHARD \\ From The Cardiac Department, Guy's Hospital \\ Received November 3, 1954
}

Existing knowledge of respiratory function in congenital heart disease is limited. Pioneer studies by Campbell et al. (1923) on four polycythæmic patients and one with pulmonary stenosis suggested an increase in resting ventilation, with compensatory decreases in the carbon dioxide fixing power of the blood. More recently, other workers (Bing et al., 1948; Davison et al., 1953; and Holling, 1952) have confirmed that there is a resting hyperpnœa in patients with a central venous-arterial shunt, but there have been no previous studies of respiration in other forms of congenital heart disease.

The present paper describes observations on the pattern of respiration in a number of forms of congenital heart disease, cyanotic and acyanotic. The pattern of external respiration has been examined, and an explanation of the observed hyperventilation has been sought in changes of carbon dioxide equilibria and of other variables affecting the respiratory system.

\section{METHODS}

Ventilatory Measurements. The resting ventilation rate, tidal volume, and respiratory minute volume have been obtained for a group of 91 patients by analysis of spirometer tracings. In a sub-group of 36 cases, the minute volume has also been determined by four Douglas bag readings. Generally there is a good correspondence between the two readings, although the spirometer tends to give a greater minute volume, since the patient is in this case breathing oxygen. Four resting alveolar samples were collected from each of the smaller group - two in the morning and two in the afternoon.

Cardiac Catheterization. The technique used in this hospital has been described previously (Holling and Zak, 1950). Arterial samples were collected anærobically in syringes lubricated with silicone fluid, and the $p \mathrm{H}$ measured at room temperature by means of a Stadie electrode system (Stadie et al., 1930); values were corrected to body temperature by the method of Rosenthal (Rosenthal, 1948). The carbon dioxide content of each specimen was measured by the Van Slyke manometric apparatus. The serum carbon dioxide content and tension were estimated by means of nomograms (Van Slyke et al., 1923 and 1928). For comparison with the alveolar gas samples, it was necessary to know also the composition of pulmonary venous blood, and in cases with a venous-arterial shunt the $p \mathrm{H}$ and carbon dioxide content found from the arterial specimen were corrected as follows.

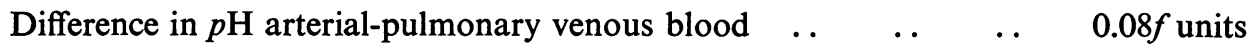

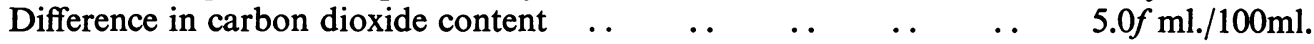

where $f$ is the fraction of arterial blood derived from the right side of the heart.

* The work described in this paper has been submitted to the University of London in part fulfilment of the requirements of a Ph.D. degree in the Faculty of Science. 
Subjects. Selection was governed simply by the degree of cooperation shown during the initial cardiac catheterization. To allow statistical treatment of the results, patients were divided into four groups.

(a) Central cyanotic, with venous-arterial shunt.

(b) Peripheral cyanotic, with reduced pulmonary flow.

(c) Acyanotic, with increased right ventricular pressure.

(d) Acyanotic, with increased pulmonary flow.

\section{PATTERN OF EXTERNAL Respiration}

Ventilatory Minute Volume. The resting minute volume seems increased in almost all cases of congenital heart disease, irrespective of whether the subject is cyanosed or not (Fig. 1). In assessing measurements of minute volume, it must be remembered that much depends on the success with which resting conditions are achieved. A usual figure for the young adult is about 4.0 litres/sq.m./min. (Baldwin et al., 1948 and Matheson et al., 1950), but it is easy to obtain higher values, and in a recent series of 27 cases the average value was 6.3 litres/sq.m./min. (Bucher, 1949). It was therefore decided to measure the minute volume in a group of nine normal subjects exposed to the same routine as the clinical material; the average value found was 4.2 litres $/ \mathrm{sq} . \mathrm{m}$./min., which conforms closely with the lower standards.

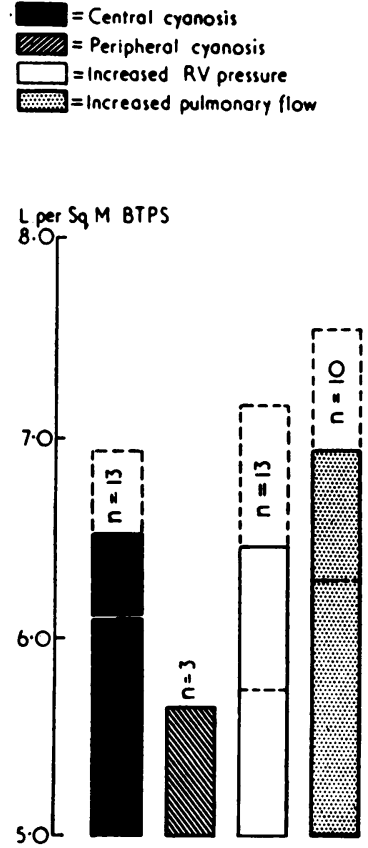

(C) Ventilotory minute volume

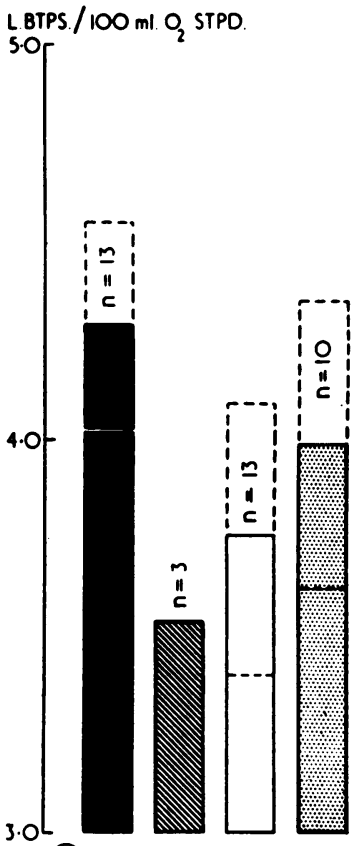

(b) Ventilotory equivolent

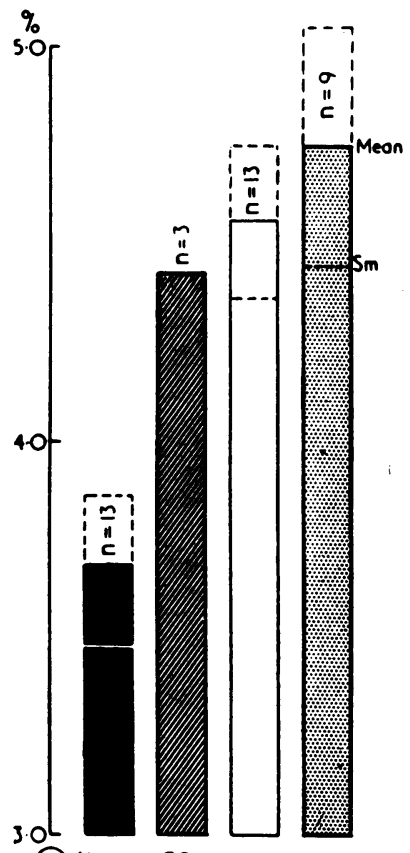

(c) Alveolar $\mathrm{CO}_{2}$ concentrotion

FIG. 1.-Minute volume, ventilatory equivalent, and alveolar carbon dioxide concentration in different types of congenital heart disease ( 39 cases). The mean and standard error are shown for each group.

Respiratory Rate and Tidal Volume. Having shown that the ventilatory minute volume is increased in the various forms of congenital heart disease, it is of some interest to consider the relative importance of changes in respiratory rate and tidal volume in the different conditions.

The rate varies considerably with age, and results have therefore been expressed as a ratio to the expected normal value, standards being based mainly on the work of Morse et al. (1949) who 
studied a large group of adolescent boys. Three of the four groups of patients show a respiratory rate ratio that is within normal limits, but the group with an increased pulmonary flow shows a ratio of $1 \cdot 23$, the difference from normal subjects and other acyanotic patients (increased right ventricular pressure group) being statistically significant (Fig. 2).

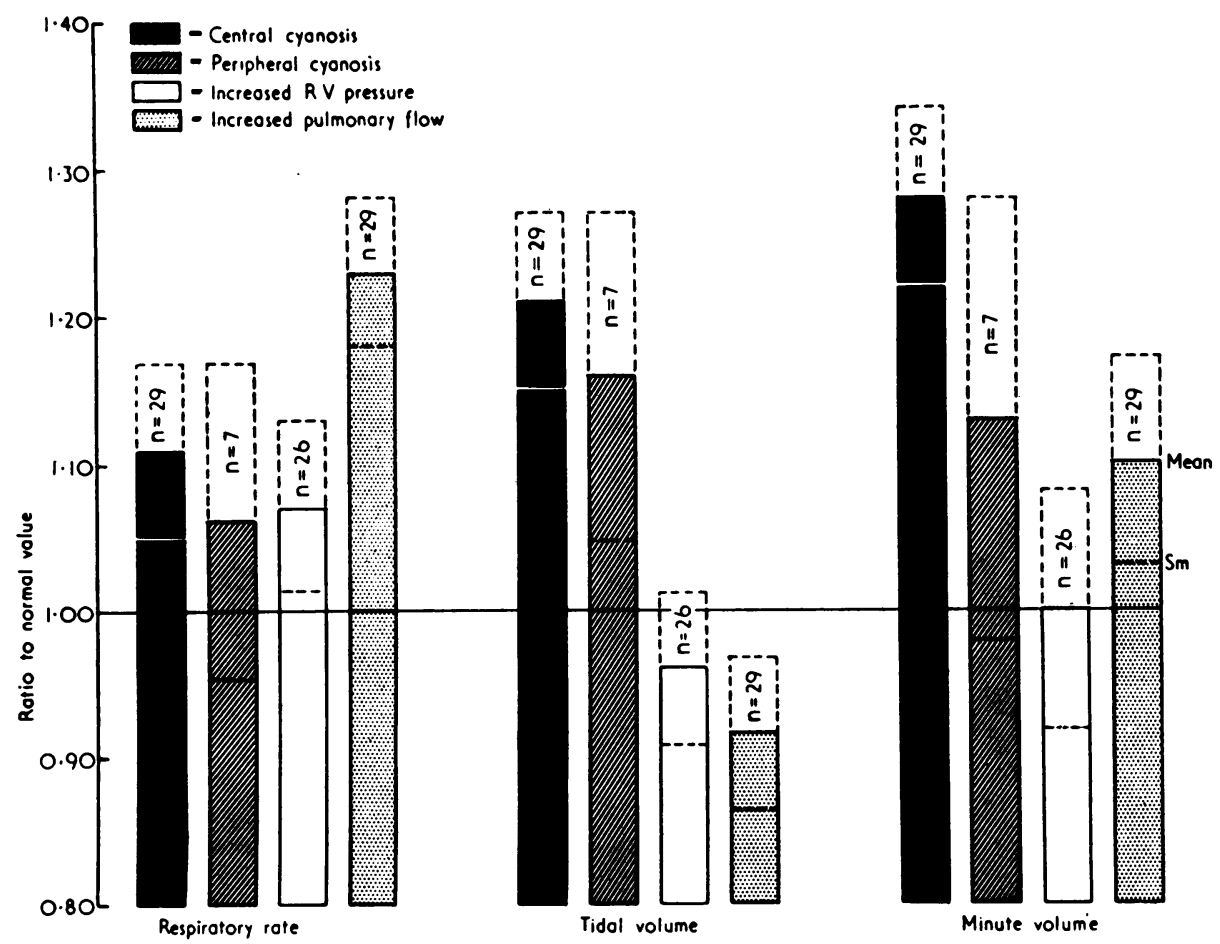

FIG. 2.-Pattern of respiration in congenital heart disease (91 cases). Respiratory rate, tidal volume, and minute volume expressed as ratio to normal values for subjects of same age and sex. The mean and standard error are shown for each group.

If tidal volume and total minute volume ratios are calculated in the same way, it can be seen that acyanotic patients with an increased right ventricular pressure show ratios that are close to unity. This is in keeping with the theoretical expectation that this group would correspond most closely with normal. Patients with an increased pulmonary flow show a smaller tidal volume, but there is still some hyperpnœa, as the shallow respiration is more than offset by a rapid respiratory rate. There is a striking difference between these two groups and the patients with cyanosis of either central or peripheral type, the cyanotic groups showing a considerable increase of tidal volume and total minute volume ratios.

Ventilatory Equivalent. Since the pattern of external respiration differs in the different classes of congenital heart disease, it is to be expected that there are corresponding differences in the efficiency of respiration in meeting the requirements of metabolism. The index taken for this purpose is the ventilatory equivalent.

The different classes of congenital heart disease show values ranging from 3.5 to 4.3 litres of ventilation BTPS per $100 \mathrm{ml}$. of oxygen STPD, and although the differences between the classes are not very large, it may be noted that higher values are observed in patients with increased pulmonary flow or central cyanosis. However, the main finding is that all classes show a greater ventilatory equivalent than the control value of 2.60 litres $/ 100 \mathrm{ml}$. found in nine normal adults and 
the previously reported standard of 2.78 litres $/ 100 \mathrm{ml}$. (Matheson and Gray, 1950). It has been known for many years (Liljestrand, 1918) that at normal levels of ventilation a slow respiratory rate is the most efficient, and efficiency declines progressively as the respiratory rate is increased. It is therefore not surprising that there is a highly significant correlation $(P=0.001)$ between respiratory rate and ventilatory equivalent in the congenital heart cases. Many patients have a greater respiratory rate than the normal adult, and this undoubtedly contributes to the increased ventilatory equivalent. In some the rate is high on account of adolescence, but in patients with an increased pulmonary flow the rate is still greater than normal even if allowance is made for age, and it would seem that other factors are helping to produce this less efficient pattern of respiration.

\section{Changes in Carbon Dioxide Equilibria}

Many of the cases of congenital disease show alterations of carbon dioxide equilibria. In some instances these are a secondary manifestation of the observed hyperpnœa, but in other cases they appear to be an important factor contributing to the increase of resting ventilation. Changes in the composition of alveolar gas and arterial blood are considered in turn.

Alveolar Carbon Dioxide Concentration. The congenital heart patients all show rather low alveolar carbon dioxide concentrations (Fig. 1), and several factors probably contribute to this. Many of the cases were children, and it is known (Haldane and Fitzgerald, 1905) that the alveolar carbon dioxide concentration is lower in childhood. In the present series, there was a fair correlation between age and alveolar carbon dioxide concentration $(p=0 \cdot 01)$. Voluntary hyperventilation immediately prior to collection of the samples was probably not of great importance, since there was no correlation between the alveolar carbon dioxide concentration and the level of resting ventilation. Samples may also have been delivered with varying efficiency, as the period of tuition was limited. However, most subjects show a satisfactory agreement between consecutive alveolar samples, and there is a good correspondence between the carbon dioxide concentration of alveolar gas and the carbon dioxide tension of pulmonary venous blood (Fig. 3). The average difference in carbon dioxide tension between the two phases is about $6 \mathrm{~mm}$. Hg; $3 \mathrm{~mm}$. of this gradient is related to systematic errors in the indirect method of measuring blood gas tension (Lambertsen et al., 1953), and part at least of the remaining difference can be attributed to the use of inspiratory alveolar samples.

Taking into account these various factors, it would seem probable that in all forms of congenital heart disease except the central cyanotic group the alveolar carbon dioxide concentration is within normal limits. Even in the central cyanotic group, the shunting of carbon dioxide rich blood into the arterial system raises the arterial carbon dioxide tension to normal values, although the tension of pulmonary venous blood is below normal. Two factors tend to maintain the carbon dioxide tension in the face of a resting hyperventilation. These are an inefficient pattern of ventilation, particularly in patients with an increased pulmonary flow, and an inefficient pulmonary circulation in many of the cyanotic patients. However, it seems possible that there may also be changes in acid/base equilibria maintaining a normal arterial and an increased tissue tension of carbon dioxide in the face of increased ventilation, and these changes are considered below.

Acid/Base Equilibria of the Blood. The arterial $p \mathrm{H}$ in all forms of congenital heart disease is slightly to the acid side of normality (Fig. 5). This would suggest that changes in acid/base balance have more than compensated for the slight hyperventilation of rest, and it represents an adaptation of some physiological importance, for with exercise hyperventilation can exceed the normal level without producing an alkalosis.

The carbon dioxide content of arterial blood is reduced in all groups except those with an increased pulmonary flow. This is in keeping with the resting hyperventilation previously noted; the normal carbon dioxide content in patients with an increased pulmonary flow is probably related in part to the lesser degree of hyperventilation in the acyanotic cases, and in part to the inefficient pattern of ventilation in this particular group.

The arterial carbon dioxide tension does not differ greatly from normal in any of the congenital 


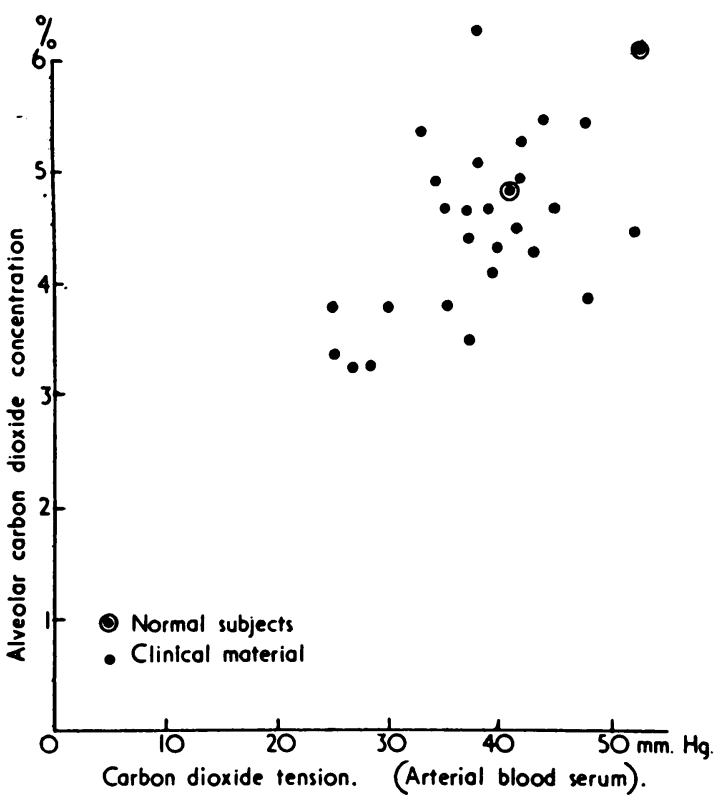

FIG. 3.-Relationship between alveolar carbon dioxide concentration and arterial carbon dioxide tension. Alveolar samples by Haldane method, arterial carbon dioxide tension by method of Rosenthal. There is a satisfactory correlation between the two measurements, slightly higher values being obtained by the Rosenthal method.

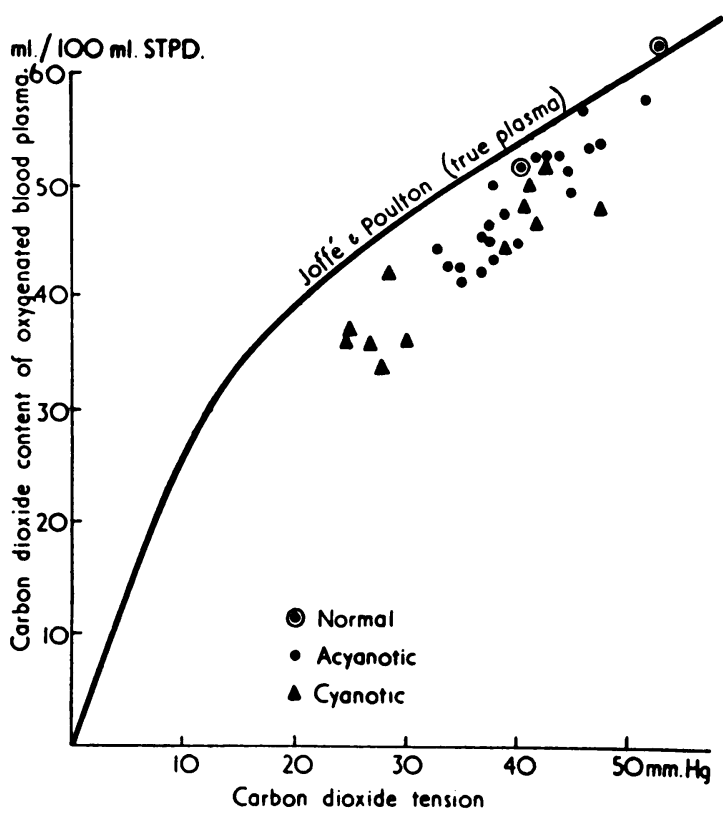

FIG. 4.-Carbon dioxide dissociation curve for arterial blood plasma. In patients with a venous-arterial shunt, the estimated pulmonary venous values have been substituted. The observed values are compared with a normal curve (Joffé).

heart patients, but within the acyanotic group there is a significant increase in tension with increased pulmonary flow, giving further evidence of inefficient ventilation in this group.

Carbon Dioxide Dissociation Curves. The clearest evidence of changes in acid/base balance can be found in a study of the carbon dioxide dissociation curves for arterial blood.

Values for two normal subjects and 33 cases of congenital heart disease are compared with a normal dissociation curve for oxygenated true plasma (Joffé and Poulton, 1920) in Fig. 4. It can be seen that while the normal subjects conform quite closely to this curve, the congenital heart patients deviate considerably, particularly in those cases where the arterial carbon dioxide tension is much reduced. The displacement of the carbon dioxide dissociation curve in a given subject shows some correlation with the level of hyperventilation in that subject $(P=0 \cdot 01-0 \cdot 001)$, suggesting that the displacement does in fact represent an adjustment of acid/base balance that tends to compensate for the resting hyperventilation. It is interesting to note that for a comparable degree of hyperventilation, the displacement of the dissociation curve is greater in the cyanotic patients, suggesting that the degree of compensation is greater in these patients. The hæmoglobin levels were distributed fairly widely, extreme values being 8.8 and $18.7 \mathrm{~g} . / 100 \mathrm{ml}$., but within these limits there was no obvious relationship between displacement of the dissociation curve and the hæmoglobin level of the blood.

Importance of Changes in Carbon Dioxide Equilibria. It remains to be considered to what extent these changes in carbon dioxide equilibria are primary factors in maintaining a resting hyperventilation. In a number of conditions, there is clearly a tendency to tissue hypercapnia. A venous-arterial shunt may introduce carbon dioxide rich blood into the systemic circulation, there is the possibility of a sluggish systemic flow, although even in severe pulmonary stenosis this 


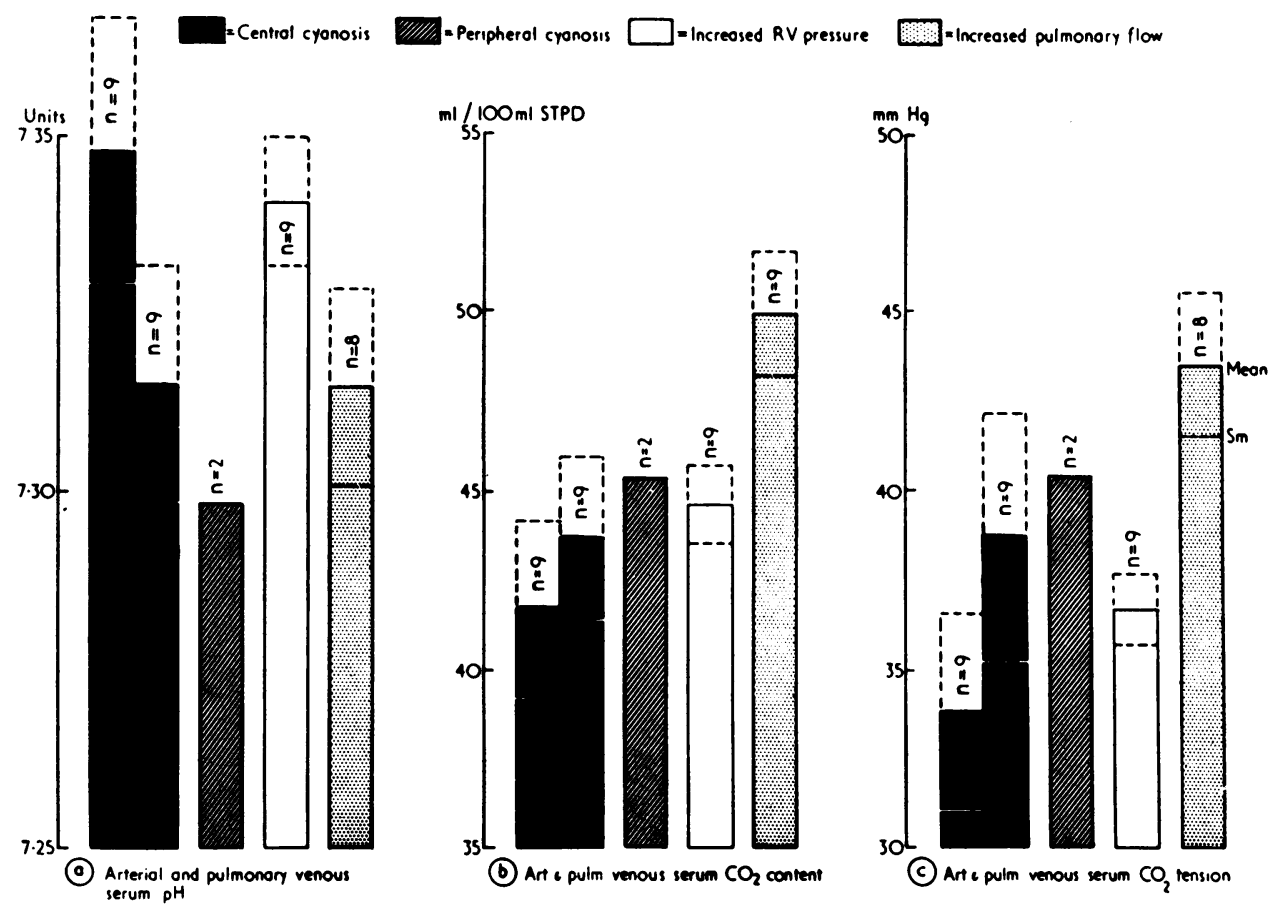

FIG. 5.-Chemical composition of arterial blood in congenital heart disease. In patients with a venous-arterial shunt (central cyanosis), the estimated composition of pulmonary venous blood is also shown. Mean and standard error indicated for each group.

is probably overcome to some extent by redistribution of the available cardiac output (Shephard, 1955), and there may be a tendency for carbon dioxide retention associated with an inefficient pattern of respiration. However, although the tissue carbon dioxide content may be normal or increased, the arterial carbon dioxide content is lowered, and an adjustment of acid/base balance is needed to keep the arterial carbon dioxide tension within normal limits. If tissue hypercapnia were the only factor maintaining the resting hyperventilation, an increased alkaline reserve might be expected, and the observed decrease suggests that other factors are of at least equal importance. A number of the other variables that may influence respiratory function are considered below.

\section{Other Variables Affecting Respiratory Function}

Oxygen Tension. The greater minute volume ratio observed in patients with central cyanosis (Fig. 2) suggests that oxygen lack is producing some stimulation of the respiratory system, probably through the activity of the chemo-receptors. However, in conformity with previous observations (Davison et al., 1953), the correlation between arterial oxygen tension and minute volume ratio is very poor. It has been suggested recently (Bjurstedt, 1946, and Rahn and Otis, 1949) that the typical response to a maintained central hypoxia is a reduction in alkali reserve, and after 6-10 hours it is difficult to detect any increase of chemo-receptor discharge. However, even if there is a transfer of emphasis from hypoxia to a relative hypercapnia with maintained exposure of the respiratory system to low oxygen tensions, it remains convenient to consider the primary stimulus of oxygen lack as one feature that is contributing to the hyperventilation in patients with central cyanosis.

Medullary hypoxia does not seem of great importance in the resting state, although there is some evidence of medullary depression after exercise, such as the appearance of Mayer waves in the systemic blood pressure record (Shephard, 1954). 
Pulmonary Blood Volume. The pulmonary blood volume has not been measured directly in the present series of patients, but an interesting correlation between tidal volume and pulmonary blood flow has been observed, and probably this can be interpreted as a respiratory response to a change in pulmonary blood volume. Previous workers (Rabinowitch, 1923, and Richards et al., 1953) have described a decrease of vital capacity in conditions where pulmonary blood flow is increased, and in the present observations the tidal volume diminishes progressively as the pulmonary flow increases (Fig. 6).

The significance of this relationship has been tested in two ways. For the first test, observations have been divided into four arbitrary groups, according to the level of pulmonary flow, and the tidal volume has been compared in the four groups.

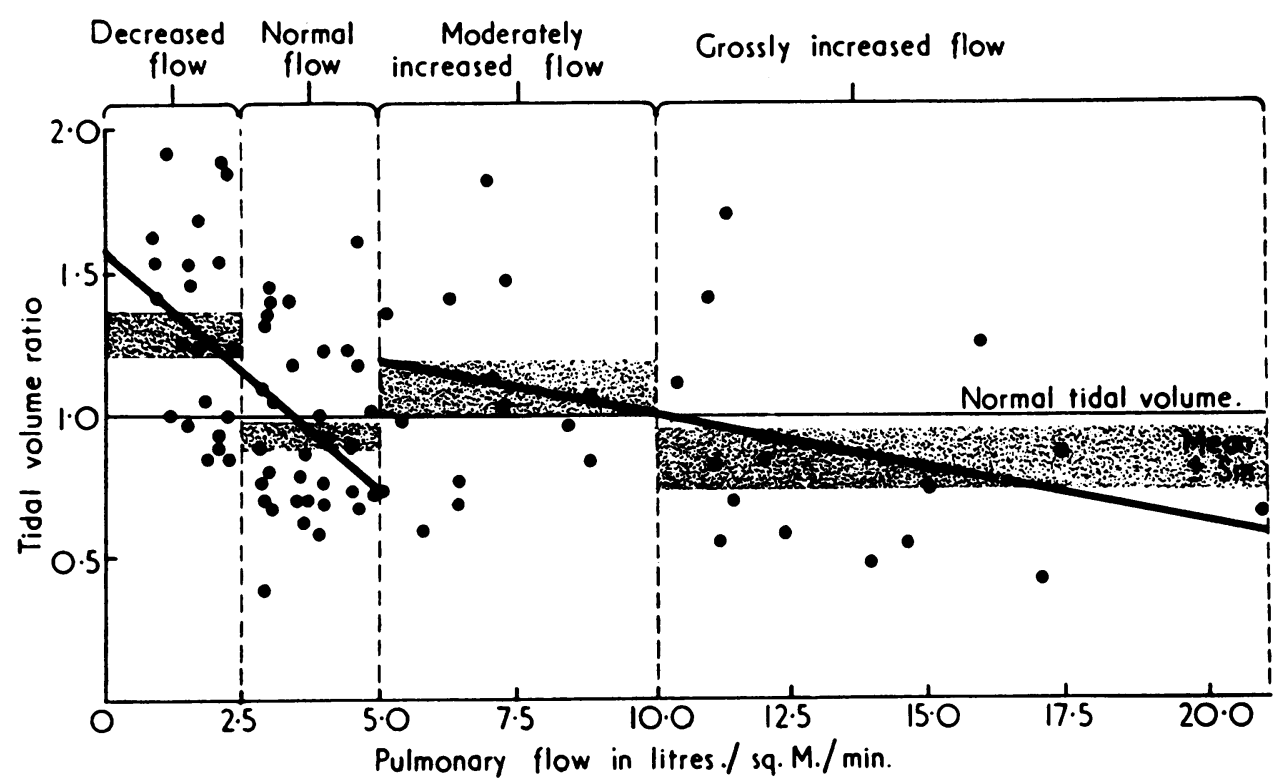

Fig. 6.-Relationship between tidal volume and level of pulmonary flow. According to the level of flow the 91 cases have been divided into four groups. The mean and standard error is shown for each group. Linear regressions fitted by method of least squares.

From this comparison, it is clear that the degree of correlation is very much greater in patients with a normal or decreased flow than in those with an increased flow. For the second test it was therefore decided to fit two linear regression lines, taking as an arbitrary dividing line a flow of 5 1./sq.m./min. The linear relationship is significant at both levels of flow $(P<0.001$ and $0.05-0.02$ respectively), and the difference between the two gradients is also highly significant.

It seems probable that the explanation of the principal relationship between tidal volume and pulmonary flow lies in associated changes of pulmonary blood volume. In the pulmonary circulation, increases of blood flow are typically associated with peripheral dilatation of small vessels rather than steeper pressure gradients between pulmonary artery and pulmonary vein (Ochsner, 1951), and a difference of blood volume may be expected in any condition where pulmonary flow is altered. It may be suggested that the increase of blood volume in turn alters the resistance of the lungs to expansion, causing the patient to adopt a rapid and shallow type of respiration. Similarly, if the pulmonary flow is less than normal the resistance of the lungs to expansion is decreased, and the tendency is to adopt the more economical pattern of slower and deeper respiration. However, other factors become involved in the correlation. In the central cyanotic group the magnitude of the right-to-left shunt is to some extent influenced by the level of pulmonary flow, and in the peripheral cyanotic group the degree of tissue hypoxia and associated hypercapnia is 
largely dependent on the level of pulmonary flow. These additional factors are probably sufficient to explain the steeper gradient of the regression observed under the conditions of reduced flow.

Baro-receptor Discharge. The various forms of congenital heart disease show considerable differences of pressure relationships in the systemic and pulmonary circulations, and this could give rise to corresponding differences in the pattern of baro-receptor impulses reaching the respiratory centre. However, recent experimental work (Landgren, 1952, and Neil et al., 1949) suggests that this factor is not of great importance. Observations on the carotid sinus have shown that the receptors discharge in response to a change of mean pressure, and if an increased pressure is maintained adaptation of the endings usually occurs. Other adaptive mechanisms, such as an alteration in the distensibility of the baro-sensitive area, or an alteration of sensitivity to these impulses in the medullary centres may also be brought into play, and it seems unlikely that the level of resting respiration is greatly influenced by these abnormal pressure relationships. Positive evidence to support this view is to be found in the pattern of respiration in patients with pulmonary stenosis. Here there is a gross increase of right ventricular pressure, and yet the pattern of respiration seems very normal (Fig. 2).

Circulation Time. The respiratory importance of the circulation time is that it gives a useful index of the degree of coordination between tissue requirements and the level of ventilation; if the transport of chemical stimuli to the respiratory centre is delayed, the ventilatory response will be correspondingly retarded.

The circulation time has been measured in a number of cardiac conditions, and in mitral stenosis it appears to be increased, especially in the pulmonary circuit (Tarr et al., 1933; Cannon et al., 1939; and Gubner et al., 1939). However, the dye method (Swan and Wood, 1953) has shown normal appearance and build up times in pulmonary stenosis and in patients with left-to-right shunts, suggesting that in congenital heart disease alterations in the calibre of the pulmonary vessels serve to maintain a normal pulmonary circulation time over a wide range of flow rates. On the other hand, some congenital heart patients show a delayed ventilatory response to exercise (Davison et al., 1953), and in the present series the response of the congenital heart patients to a 5 per cent mixture of carbon dioxide was rather slower than in normal subjects. It is difficult to be certain that these differences can be attributed to variations in the circulation time, since such changes in ventilation are initiated partly via higher centres of the brain, and the normal subjects were quicker to appreciate that carbon dioxide was being administered, but it is clearly impossible to state with certainty that stimuli reach the respiratory centre via the blood stream with equal rapidity in all forms of congenital heart disease.

Physical Development. The effector side of the respiratory system is not grossly impaired even in the more severe forms of congenital heart disease. Where central cyanosis is severe, particularly in cases of transposition and pulmonary atresia, general physique may be below average; there may also be moderate kyphosis or a Harrison's sulcus, and if there has been cardiac hypertrophy from an early age there may also be some prominence of the left chest wall. However, these changes were not usually very severe, and it seems unlikely that many of these patients present physical factors sufficient to affect the pattern of resting respiration or limit the response to a mild respiratory stimulus.

\section{DisCUSSION}

It would appear from the ventilatory measurements that the resting respiratory minute volume is greater than the accepted normal value in a number of types of congenital heart disease, acyanotic as well as cyanotic. However, it is important to be certain that these are real changes, and not due merely to voluntary hyperventilation. In the present observations, care was taken to reassure the subjects and allow them to become accustomed to the use of respiratory apparatus. Objective evidence of the success of these measures is to be found in the relatively normal respiratory rate, and the absence of a correlation between the level of resting ventilation and the alveolar carbon dioxide concentration. Study of the chemical composition of the blood gives further evidence of 
a genuine increase of ventilation, since there is a reduction in the carbon dioxide content of the blood, with compensatory changes in acid/base balance which tend to maintain a normal arterial carbon dioxide tension. However, it is still possible that part of the hyperventilation is of voluntary origin, and it is therefore more satisfactory to compare the different forms of congenital heart disease rather than attempt a direct comparison with healthy subjects.

In cyanotic patients, the increase in ventilation is achieved mainly by a larger tidal volume, and the respiratory rate corresponds fairly closely with that found in patients whose only physiological abnormality is an increase of right ventricular pressure. It would seem that a number of variables contribute to this increase of tidal volume, perhaps the most important being a true or relative hypercapnia of the medullary centres, brought about by the primary factors of a venous-arterial shunt and a reduced pulmonary flow. The pattern of increased respiration is probably influenced to some extent by the mechanical effects of changes in the level of pulmonary flow, but the degree of correlation between tidal volume and flow is increased by the fact that the degree of tissue hypoxia and hypercapnia is also largely dependent on the rate of pulmonary flow.

In the acyanotic patients, there is an increase primarily of respiratory rate, and it would seem that this rapid, shallow, and inefficient pattern of respiration is related largely to an increase of pulmonary flow. The mechanical basis is a matter for conjecture, but it may be postulated that the increase of flow produces an increased viscosity of the lungs ("lungenstarre" effect), and this in turn favours a shallow pattern of breathing. It is clear that in the presence of a left-to-right shunt, the acyanotic patients fail to achieve a normal pattern of respiration, although the abnormality seems mainly mechanical rather than chemical in type. On the other hand, the acyanotic patients with only an increase of right ventricular pressure show no significant abnormality of respiration, and this group therefore provides the best control with which the other patients may be compared.

In none of the types of congenital heart disease studied is the degree of hyperventilation very great, and in most instances a fairly adequate explanation can be found in changes outside the respiratory centre. It is therefore probable on the evidence of resting respiration alone that there is no large change in the sensitivity of the respiratory centre.

\section{SUMMARY}

The pattern of resting respiration has been studied in 91 cases of congenital heart disease, and to facilitate this analysis patients have been divided into four classes: central cyanotic, peripheral cyanotic, acyanotic with increased right ventricular pressure, and acyanotic with increased pulmonary flow.

Most patients show some evidence of hyperventilation at rest. In the cyanotic classes this is due to an increase of tidal volume, rather greater in those with central cyanosis. Of the acyanotic, those with only an increase of right ventricular pressure show a normal pattern of respiration, but those with an increased pulmonary flow show some hyperventilation associated with a rapid respiratory rate. Calculation of the ventilatory equivalent shows that in most instances the hyperventilation is inefficient from the standpoint of oxygen exchange.

The chemical composition of the blood shows changes typical of a mild compensated hyperventilation. There is a decreased carbon dioxide content and alkali reserve, with relatively normal carbon dioxide tensions and $p \mathrm{H}$ values in the arterial blood.

Examination of the variables affecting the respiratory system suggests that the hyperventilation in cyanotic patients is predominantly due to a true or relative hypercapnia, while in patients with an increased pulmonary flow it is thought that an increased viscosity of the lung tissues is responsible for the shallow and inefficient pattern of respiration. Other variables, such as the level of baroreceptor discharge, the circulation time, and the physical development of the respiratory apparatus seem of relatively minor importance.

My thanks are due to Dr. Campbell for his helpful advice during the preparation of this paper, to the Department of Medical Illustration for the figures, and to Miss Scott for valued technical assistance. 


\section{REFERENCES}

Baldwin, E., Cournand, A., and Richards, D. W. (1948). Medicine, 28, 201.

Bing, R. J., Vandam, L. D., Handlesman, J. C., Campbell, J. A., Spencer, R., and Griswold, H. E. (1948). Bull. Johns Hopk. Hosp., 83, 439.

Bjurstedt, A. G. H. (1946). Acta physiol. scand., 12, Supp. 38.

Bucher, K. (1949). Helv. physiol. pharm. acta. 7, 470.

Campbell, J. M. H., Hunt, G. H., and Poulton, E. P. (1923). J. Path. Bact., 26, 234.

Cannon, E. F., Lucia, S. P., and Benson, E. H. (1939). Proc. Soc. exp. Biol., N.Y., $42,237$.

Davison, P. H., Armitage, G. H., and Arnott, W. M. (1953). Brit. Heart J., 15, 222.

Gubner, R., Schnur, S., and Crawford, J. H. (1939). J. clin. Invest., 18, 395.

Haldane, J. S., and Fitzgerald, M. P. (1905). J. Physiol., 32, 486.

Holling, H. E. (1952). Clin. Sci., 11, 283. and Zak, G. (1950). Brit. Heart J., $12,153$.

Joffé, J., and Poulton, E. P. (1920). J. Physiol., 54, 129.

Lambertsen, C. J., Kough, R. H., Cooper, D. Y., Emmel, G. L., Loeschcke, H. H., and Schmidt, C. F. (1953). J. appl. Physiol., 5, 803.

Landgren, S. (1952). Acta physiol. scand., 26, 1 and 35.

Liljestrand, G. (1918). Skand. Arch. Physiol., 35, 199.

Matheson, H. W., and Gray, J. S., (1950). J. clin. Invest., 29, 688.

Morse, M., Schlutz, F. W., and Cassels, D. E. (1949). J. appl. Physiol., 1, 683.

Neil, E., Redwood, C. M. R., and Schweitzer, A. (1949). J. Physiol., 109, 259.

Ochsner, A. (1951). Amer. J. Physiol., 168, 200.

Rabinowitch, I. M. (1923). Arch. intern. Med., 31, 910.

Rahn, H., and Otis, A. B. (1949). Amer. J. Physiol., 157, 445.

Richards, D. G. B., Whitfield, A. G. W., Arnott, W. M., and Waterhouse, J. A. H. (1953). Brit. Heart J., $15,83$.

Rosenthal, T. B. (1948). J. biol. Chem., 173, 25.

Shephard, R. J. (1954). Guy's Hosp. Rep., 103, 269. (1955). Brit. Heart J., 17, 98.

Stadie, W. C., O'Brien, H., and Lang, E. P. (1930). J. biol. Chem., 91, 243.

Swan, H. J. C., and Wood, E. H. (1953). Proc. Mayo Clin., 28, 95.

Tarr, L., Oppenheimer, B. S., and Sager, R. V. (1933). Amer. Heart J., 8, 766.

Van Slyke, D. D., and Sendroy, J. (1928). J. biol. Chem., 79, 781.

-, Wu, H., and McLean, F. C. (1923). J. biol. Chem., 56, 765. 